\title{
An investigation of diverticular disease among black patients undergoing colonoscopy at Dr George Mukhari Academic Hospital, Pretoria, South Africa
}

\author{
M Vally, MB ChB; M Z Koto, MB ChB, FCS (SA), FACS; M Govender, MB ChB, FCS (SA) \\ Department of General Surgery, Sefako Makgatho Health Sciences University, Pretoria, South Africa
}

Corresponding author: M Vally (moinuddeen.vally@gmail.com)

Background. Diverticular disease was previously thought to be non-existent in the black African population. Studies over the past four decades, however, have shown a steady increase in the prevalence of the disease.

Objective. To report on the profile and current prevalence of diverticular disease in the black South African (SA) population at Dr George Mukhari Academic Hospital, Pretoria, SA.

Methods. A retrospective descriptive study was performed in black SA patients who were diagnosed with diverticular disease by colonoscopy between 1 January and 31 December 2015.

Results. Of 348 patients who had undergone colonoscopies and who were eligible for inclusion in this study, 47 were diagnosed with diverticular disease - a prevalence of $13.50 \%$ (95\% confidence interval 10.30 - 17.50). The greatest number of patients diagnosed were in their 7 th and 8 th decades, with an age range of 46 - 86 (mean 67 ) years. There was a female predominance of $57.45 \%$. Lower gastrointestinal bleeding was the most common $(65.96 \%)$ indication for colonoscopy. The left colon was most commonly involved $(72.34 \%)$, followed by the right colon (55.31\%). A substantial number of patients had pancolonic involvement (27.65\%).

Conclusion. This retrospective study suggests that there has been a considerable increase in the prevalence of diverticular disease among black South Africans, possibly owing to changes in dietary habits and socioeconomic status.

S Afr Med J 2017;107(2):137-139. DOI:10.7196/SAMJ.2017.v107i2.12007

Diverticular disease is an acquired condition of the colon, characterised by protrusions of the colonic mucosa and submucosa through the muscular layers of the colon, which tend to occur at anatomically weak points where blood vessels penetrate the muscular layer. ${ }^{[1-3]}$

Diverticular disease has been considered a lifestyle disease of western countries. Age, urbanisation and low-fibre diets are thought to be risk factors for developing the disease. The majority of patients $(>80 \%)$ remain asymptomatic and are diagnosed incidentally. In those who are symptomatic, the most common presenting symptoms are rectal bleeding, abdominal pain and constipation. ${ }^{[2-5]}$

The highest prevalence of diverticular disease is found in the USA, Europe and Australia, where up to $50 \%$ of the population over 60 years of age and $60 \%$ of persons over 80 years old have the disease. This is in stark contrast with black and Asian populations, where the prevalence has been reported as less than $0.5-1.0 \%$. The most recent studies, however, have reported a prevalence of more than $10 \%$ in black patients. ${ }^{[1,2,6]}$

The prevalence of the disease in black South Africans is unknown, as studies in the South African (SA) context are dated. These studies do not adequately reflect the socioeconomic and lifestyle changes that have occurred since the country attained democracy in $1994 .^{[7,8]}$

To determine the current prevalence and characteristics of diverticular disease in black South Africans, we retrospectively reviewed colonoscopy reports from the endoscopy suite at Dr George Mukhari Academic Hospital, Pretoria, SA from January to December 2015.

\section{Methods}

This was a single-centre, retrospective, descriptive study of all cases of diverticular disease diagnosed by colonoscopy in black patients between 1 January and 31 December 2015 at the endoscopy suite at Dr George Mukhari Academic Hospital.
Besides the indication for colonoscopy, the records used for analysis provided no further information regarding the medical, surgical, dietary and social circumstances of the patient, and did not indicate where the patient resides or was referred from.

Inclusion criteria were the following: all black patients diagnosed with diverticular disease by colonoscopy during the study period; patients over 18 years of age; and patients in whom a complete colonoscopy was not possible, but diverticuli were identified in the visualised portion of the colon (usually left sided). Non-black patients (e.g. Asian, white, coloured), patients under 18 years, and those with poor bowel preparation were excluded from the study.

Data were retrospectively collected from the endoscopy suite records. Duplicate paper records from January to March 2015 were analysed, as well as records from the electronic Endobase computer system (Olympus, Japan) from April to December 2015. Two records $(0.5 \%)$ of 384 colonoscopies were not captured owing to illegible handwriting.

Data, including patient demographics, indications for colonoscopy and colonoscopic findings, were collected on individual data collection sheets and then collated onto a Microsoft Excel (USA) spreadsheet for further analysis.

Demographic and clinical details were summarised descriptively. Continuous data (e.g. age) were summarised by means, standard deviations, medians, interquartile ranges, and minimum and maximum values. Categorical data (e.g. gender) were summarised by frequency counts and a percentage calculation. The prevalence was calculated with a $95 \%$ confidence interval (CI).

All statistical analyses were performed on SAS 9.4 (SAS Institute Inc., USA), and sample size calculation was done using nQuery Advisor, Release 7.0 (J D Elashof, USA). Ethical approval was obtained 
from the Sefako Makgatho Health Sciences University Research Ethics Committee (SMUREC) (ref. no. SMUREC/M/63/2016:PG).

\section{Results}

\section{Sample size and prevalence}

During the study period, 384 colonoscopies were performed. Of these, 348 were eligible for inclusion in the study. Forty-seven cases of diverticular disease were diagnosed by colonoscopy during this period.

The prevalence of diverticular disease calculated in this sample population was $13.50 \%$, with a $95 \% \mathrm{CI}$ of $10.30-17.50$. This prevalence is reflective of our sample population - a select set of patients who underwent colonoscopy because of a specific indication, and as such may not reflect the overall population prevalence among blacks in SA.

\section{Demographics}

Of the 47 patients with diverticular disease, 20 were male and 27 female $-42.50 \%$ and $57.50 \%$, respectively.

The age of patients ranged from 46 to 86 years. The majority of cases, regardless of gender, were in their 7 th and 8 th decades (Table 1).

There were five cases for which age was not recorded. The mean age for cases of diverticular disease, where the age is known $(n=42)$, was 67.4 years, with a standard deviation (SD) of 9.6 years. The median age was 68 years and the interquartile range $62-73$ years. This is further summarised according to gender in Table 2.

\section{Indications for colonoscopy}

The indication for colonoscopy for the majority of patients diagnosed with diverticular disease was lower gastrointestinal bleeding $(n=31$; $65.96 \%)$. Because of the retrospective nature of this study, it was not possible to determine the extent of bleeding that prompted colonoscopy or follow-up management for bleeding. Other indications included changes in bowel habit $(n=6 ; 12.77 \%)$, abdominal pain $(n=4 ; 8.50 \%)$, anaemia $(n=3 ; 6.38 \%)$ and work-up for colon cancer $(n=3 ; 6.38 \%)$.

\section{Pattern of colonic involvement}

For descriptive purposes the colon was divided anatomically into three segments: right side (caecum to hepatic flexure); transverse (hepatic flexure to splenic flexure); and left side (splenic flexure to rectum). When all three segments were involved, it was referred to as pancolonic. Table 3 summarises the pattern of involvement as reported at colonoscopy.

The left-side-only pattern and the pancolonic pattern were most commonly reported ( $n=13$, respectively; $27.65 \%$ ). The right side alone was involved in $19.14 \%$ of patients, and almost half of patients $(n=22 ; 46.80 \%)$ had multi-segment involvement. In more than a quarter $(27.65 \%)$ of cases the entire segment was involved.

\section{Segmental involvement}

The segment most commonly involved in isolation was the left side (27.65\%). The frequency of a segment being involved increased once those with multi-segmental involvement were analysed further.

The left side was the most frequently involved segment overall, followed by the right side, and the transverse colon. Even when pancolonic involvement was excluded, almost two-thirds (61.76\%) had left-sided involvement. Fig. 1 shows the frequency of involvement of each segment, taking multi-segment and pancolonic involvement into consideration.

\section{Pattern of involvement $v$. indication for colonoscopy}

An attempt was made at correlating the segment involved and the indication for colonoscopy to establish if there was any significant
Table 1. Summary of cases per decade

\begin{tabular}{llll}
\hline Age (years) & $\boldsymbol{n}$ & Male & Female \\
\hline $40-49$ & 1 & 0 & 1 \\
$50-59$ & 6 & 3 & 3 \\
$60-69$ & 16 & 6 & 10 \\
$70-79$ & 15 & 7 & 8 \\
$80+$ & 4 & 2 & 2 \\
Unknown & 5 & 2 & 3 \\
Total & 47 & 20 & 27 \\
Youngest & - & 50 & 46 \\
Oldest & - & 83 & 86
\end{tabular}

Table 2. Summary of age data

\begin{tabular}{llll}
\hline Age data & All cases & Male & Female \\
\hline Number $(n)$ & 42 & 18 & 24 \\
Age (years), mean & 67.40 & 68.90 & 66.25 \\
SD & 9.60 & 9.15 & 9.96
\end{tabular}

Table 3. Summary of pattern of involvement

\begin{tabular}{llll}
\hline Segment & $\boldsymbol{n ( \% )}$ & Male & Female \\
\hline Left side only & $13(27.65)$ & 5 & 8 \\
Left side and transverse & $5(10.64)$ & 2 & 3 \\
Transverse only & $3(6.38)$ & 2 & 1 \\
Right side only & $9(19.14)$ & 4 & 5 \\
Right and left sides & $3(6.38)$ & 1 & 2 \\
Right side and transverse & $1(2.13)$ & 1 & 0 \\
Pancolonic & $13(27.65)$ & 5 & 8 \\
Total & $47(100)$ & 20 & 27
\end{tabular}

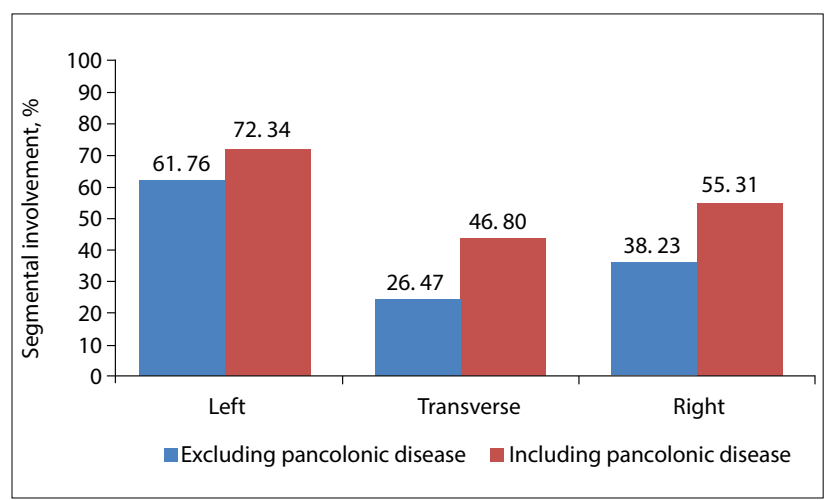

Fig. 1. Comparison of segmental involvement with and without pancolonic involvement.

association. Fisher's exact test was applied and calculated a $p$-value of $>0.05$ ( $p=0.383$ ), which suggests that there is no significant association between an indication for colonoscopy and colonoscopic findings.

\section{Discussion}

Diverticular disease was previously thought to be rare among the black African population, with a prevalence that was possibly as low as $1.0 \%$. The most recent publication reported a prevalence of $\sim 10.0 \%{ }^{\left[{ }^{[6]}\right.}$ 
Table 4. Summary of African studies on diverticular disease $e^{[6-9,11,12]}$

\begin{tabular}{|c|c|c|c|c|c|c|c|}
\hline & $\begin{array}{l}\text { Archampong } \\
\text { et al. }{ }^{\left[{ }^{9]}\right.} 1978\end{array}$ & $\begin{array}{l}\text { Segal and } \\
\text { Walker, }^{[7]} 1982\end{array}$ & $\begin{array}{l}\text { Madiba and } \\
\text { Mokoena, }{ }^{[8]} \\
1994\end{array}$ & $\begin{array}{l}\text { Kiguli-Malwadde } \\
\text { and Kasozi, }{ }^{[11]} \\
2002\end{array}$ & $\begin{array}{l}\text { Alatise } \\
\text { et al., }{ }^{[12]} 2013\end{array}$ & $\begin{array}{l}\text { Oluyemi and } \\
\text { Odeghe, }{ }^{[6]} \\
2016\end{array}$ & Current study \\
\hline Country & Ghana & SA & SA & Uganda & Nigeria & Nigeria & SA \\
\hline \multicolumn{8}{|l|}{ Pattern (\%) } \\
\hline Pancolonic & 75 & - & - & 10 & 85 & 35 & 28 \\
\hline Left side & - & - & 77 & Majority & - & 96 & 72 \\
\hline Right side & - & - & 62 & - & - & - & 55 \\
\hline LGIB (\%) & 50 & 50 & 74 & 40 & 70 & 56 & 66 \\
\hline \multicolumn{8}{|l|}{ Gender (\%) } \\
\hline Male & 81 & 38 & 39 & 52 & 72 & 82 & 43 \\
\hline Female & 19 & 62 & 61 & 48 & 28 & 18 & 58 \\
\hline \multicolumn{8}{|l|}{ Age (years) } \\
\hline Range & $45-79$ & - & - & $42-80$ & $41-85$ & $46-94$ & $46-86$ \\
\hline Median & 54 & 62 & - & 60 & 64 & - & 68 \\
\hline Peak & - & - & $51-64$ & - & - & - & - \\
\hline Mean & - & - & - & - & - & 68 & - \\
\hline Cases/years & $14 / 3$ & $42 / 3$ & $26 / 5$ & $33 / 5$ & $40 / 5$ & $28 / 5$ & $47 / 1$ \\
\hline
\end{tabular}

Our results show that there has been a substantial increase in the prevalence of diverticular disease in our sample population. We report a prevalence of $13.50 \%$, which is similar to that of $10.60 \%$ reported by Oluyemi and Odeghe ${ }^{[6]}$ from Nigeria. It is higher than those reported by earlier studies of black African patients.

The pathogenesis of the disease is possibly due to lifestyle factors. It is likely that the traditional African diet, which is naturally high in fibre, is protective against diverticular disease. Painter and Burkitt, ${ }^{[5]}$ in 1971, provided an extensive historical and epidemiological review of the role of diet and lifestyle in the pathogenesis of the disease. Since 1994, when SA obtained democracy, there has been significant urbanisation of the black community. This is coupled to a generally improved socioeconomic status and a probable change in dietary habits.

The patients in this study are from an urban area, where there is an increasing intake of fast food and a more western-type diet.

Interestingly, apart from the considerably higher prevalence of diverticular disease, our results are similar to those of two previous studies from SA, i.e. Segal and Walker ${ }^{[7]}$ and Madiba and Mokoena. ${ }^{[8]}$ Comparisons between age, gender and presenting symptoms are fairly consistent in the three studies.

Compared with studies from other African countries, however, there are some differences. Their reports suggest that diverticular disease is more common in males than females and some studies report a much higher rate of pancolonic disease. These studies are summarised in Table $4 .{ }^{[6-9,11,12]}$

Whether our findings can be attributed solely to changes in dietary habits and socioeconomic changes is unclear. An additional explanation for such an increased prevalence could be that black patients in SA currently have better access to appropriate, modern diagnostic modalities than before democracy was instituted in 1994.

There are some limitations and biases in our study. Firstly, the centre where the study was conducted is a large referral centre, where the majority of patients referred for investigations are symptomatic. The results of this study, therefore, describe the prevalence of diverticular disease in symptomatic patients. In western countries, it is reported that up to $80 \%$ of patients with diverticular disease remain asymptomatic.
The prevalence of diverticular disease among black South Africans may therefore be considerably higher.

Secondly, this was a retrospective study and as such only the information contained in the colonoscopy reports was available for analysis. Possible readmissions for recurrent symptoms, surgical management or complicated disease were not accounted for. There was no direct patient follow-up after colonoscopy.

\section{Conclusion}

There has been a substantial increase in the prevalence of diverticular disease among black South Africans. We report a prevalence of $13.50 \%$ in this study, which is likely to continue to increase with further urbanisation and adoption of westernised diets. Clinicians should have a higher index of suspicion for this condition in black patients, which may fit the clinical picture of diverticular disease. With an increase in prevalence, there will also be an increase in the number of related complications. Prospective studies are recommended to investigate the natural clinical course of the disease in this population group.

. Weizman AV, Nguyen GC. Diverticular disease: Epidemiology and management. Can J Gastroenterol 2011;25(7):385-389. http://dx.doi.org/10.1155/2011/795241

Stollman N, Raskin JB. Diverticular disease of the colon. Lancet 2004; 363(9409):631-639. http://dx.doi org/10.1016/s0140-6736(04)15597-9

ren IC, Bundgaard L, Elbrond H, et al. Danish national guidelines for treatment of diverticular disease. Dan Med J 2012;59(5):C4453.

. Matrana MR, Margolin DA. Epidemiology and pathophysiology of diverticular disease. Clin Colon Rectal Surg 2009;22(3):141. http://dx.doi.org/10.1055/s-0029-1236157

Painter NS, Burkitt DP. Diverticular disease of the colon: A deficiency disease of Western civilization. BMJ 1971;2(5759):450-454

6. Oluyemi A, Odeghe E. Diverticular disease at colonoscopy in Lagos State, Nigeria. Niger Med J 016;57(2):110. http://dx.doi.org/10.4103/0300-1652.182072

Segal I, Walker AR. Diverticular disease in urban Africans in South Africa. Digestion 1982;24(1):42-46.

8. Madiba TE, Mokoena T. Haemorrhage - the main presenting feature of diverticular disease of the colon in blacks. S Afr Med J 1994:84(2):83-85

Archampong EQ, Christian F, Badoe EA. Diverticular disease in an indigenous African community. Ann Roy Coll Surg 1978:60(6):464.

10. Calder JF. Diverticular disease of the colon in Africans. BMJ 1979;1(6176):1465, http://dx.doi org/10.1136/bmi 1.6176.1465-a

1. Kiguli-Malwadde E, Kasozi H. Diverticular disease of the colon in Kampala, Uganda. Afr J Health Sci 2002;2(1):29-32.

12. Alatise OI, Arigbabu AO, Lawal OO, et al. Presentation, distribution pattern, and management of diverticular disease in a Nigerian tertiary hospital. Niger I Clin Pract 2013;16(2):226-231. http://dx do org/10.4103/1119-3077.110152

Accepted 8 November 2016 